\title{
Structural Design Research Through Finite Element Method (FEM) for a Compressor Disc
}

\author{
Merin Christo J, Badarinath B G, Shivakumar S, Umesh V
}

\begin{abstract}
Compressor Discs are subjected to various loads like pressure load, tensile, compressive, buckling, temperature, gravity, etc. during its operation. There are load bearing members and non-load bearing members. The load bearing members are critical components of the disc. Due to these loading condition radial and hoop stresses are generated in the discs. When these stresses exceed yield strength of the material failure occurs. To determine the various stresses acting on a gas turbine compressor disc rotating with constant velocity, initially the Disc is modeled and analyzed using Commercial FEA codes focused on bolt holes and nominal stresses on the cracked disc (a corner crack at a hole and then a through-thickness crack between two holes) are determined. These Stresses can be accounted for the development of advanced crack growth model which can predict the propagation of crack from the critical location of the rotating disc.
\end{abstract}

Keywords: Compressor Disc, Load bearing members, Critical component, Failure, Stress, Deformation.

\section{INTRODUCTION}

Compressor disks are failure-critical components in aircraft engines that attract the most research attention in engine life management. Fatigue crack propagation is greatly relevant and need to be predicted from the critical location of the disc e.g., subjection of the bolt to a cyclic loading state. In this way for the prediction of the crack growth behavior, it is necessary to develop an advanced crack growth model that can actually take into account complex loading conditions and biaxial loading conditions. Rotating disks are often subject to biaxial or multi-axial loading conditions during the operation of the aircraft engine. The aim of this work is to examine the stresses acting in a tie bolt holes in a representative gas turbine compressor disc, with particular emphasis on the effect of biaxial stress inherent in a rotating disc. The nominal stresses on the disc (a corner at a hole, then a through-thickness \& between two holes), are determined using three-dimensional finite element elastic studies. Therefore, Conventional Linear Elastic Fracture Mechanics

Revised Manuscript Received on March 16, 2020.

* Correspondence Author

Merin Christo J*, PG student, Mechanical and Automobile Engineering, School of Engineering and Technology, Christ (Deemed to be University), Bengaluru, Karnataka, India. Email: merinchristo@gmail.com

Badarinath B G, Managing Director, Renprotech Solutions Pvt. Ltd., Bengaluru, Karnataka, India. Email: badari@renprotech.co.in

ShivaKumar S, Assistant Professor, Mechanical and Automobile Engineering, School of Engineering and Technology, Christ (Deemed to be University), Bengaluru, Karnataka, India. Email:shivakumar.s@christuniversity.in

Umesh V, Assistant Professor, Mechanical and Automobile Engineering, School of Engineering and Technology, Christ (Deemed to be University), Bengaluru, Karnataka, India. Email: umesh.v@christuniversity.in

(C) The Authors. Published by Blue Eyes Intelligence Engineering and Sciences Publication (BEIESP). This is an open access article under the CC BY-NC-ND license (http://creativecommons.org/licenses/by-nc-nd/4.0/) should be still valid for quantify the growth of short crack from the hole [1]. The objective of this work is to determine the various stresses acting on a gas turbine compressor disc rotating with constant velocity of 15000 RPM and 45000 RPM.

W.Z. Zhuang [1] studied the effect of bi-axial loading on the disc subjected to the cyclic rotational speed. He found the stress intensity factor ratio for both bi-axial and uniaxial loading condition. He studied the stress distribution around the bolt hole region for 8000 RPM and 37000 RPM. Hasan C et al. [2] studied the stress analysis on disc made of functionally graded materials (FGM). He studied the tangential and radial stress distribution and displacement of the disc by analytical and numerical methods. He found by reducing the tangential stresses the disc's rotational speed is increased. M. Kumar et al. [3] studied the fatigue crack growth in the nickel based super alloys at two temperature. He predicted crack growth in the aero-engine turbine disc. R.A Claudio et al. [4] studied the propagation of crack in a turbine disc without crack and with two types of crack. He found the critical component of the disc is the notch root and found high stresses developed in those location. Wieslaw Beres et al. [5] studied the residual life of a turbo prop engine by both experimental and numerical methods. Kumar R et al. [6] Performed the elasto plastic analysis on a turbine disc rotating with two different speeds to find the burst margins. He found that the burst margin decreases with increase in speed of rotation of disc and reduced the hoop stress. Sariti Lemi [7] done various design studies through finite element method for a gas turbine disc considering the structural and thermal effects made of Inconel 713LC Superalloy. Vyas, N.S et al [8] investigated the dynamic stress analysis of a turbine blade using life prediction algorithm and studied fatigue life prediction of blades. Horgon C.O et al. [9] investigated the stresses acting on a hollow cylinder with internal and external pressure made of functionally graded, isotropic, linearly elastic materials. Durodola, J. F.et al. [10] investigated the deformation and stress acting on a rotating disc made of functionally graded materials and compared them with theoretical results.

\section{FEA ANALYSIS}

To determine the state of stresses around the bolt hole region in the disc, a three-dimensional finite element analysis of the disc was carried out using ANSYS. The geometry of the disc is shown in Fig. 1 below;

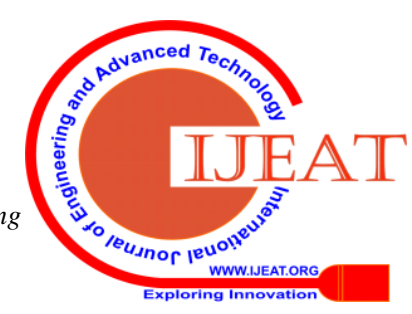




\section{Structural Design Research Through Finite Element Method (FEM) for a Compressor Disc}

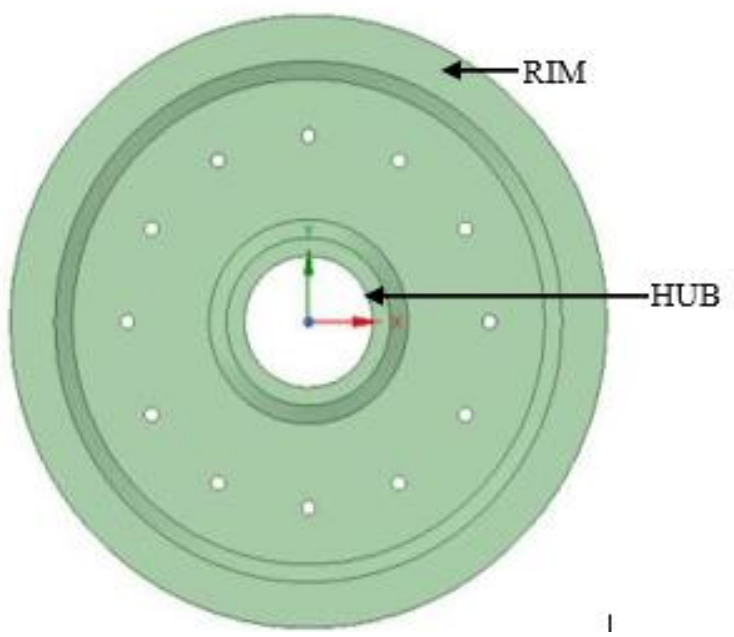

Fig. 1.Full disk model 3D

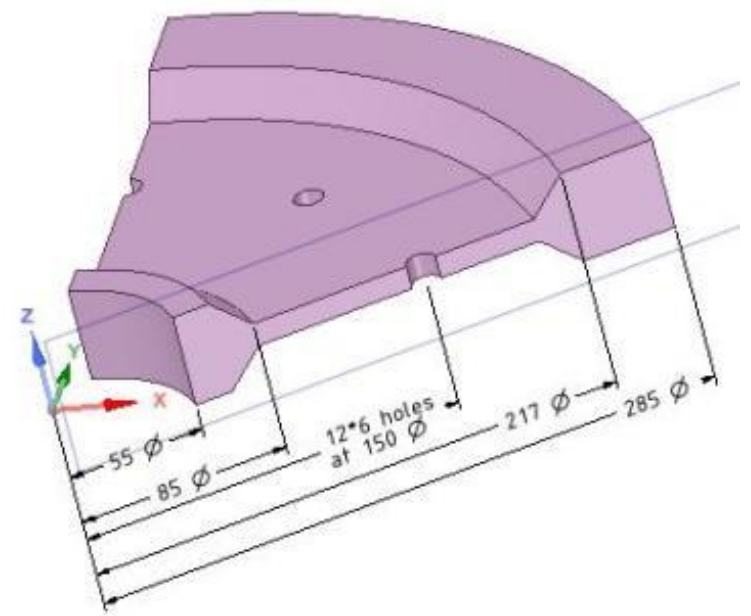

Fig. 2.Model Dimensions

The inner diameter of the disc is $55 \mathrm{~mm}$ and the outer diameter of the disc is $255 \mathrm{~mm}$. The Pitch circle diameter is $150 \mathrm{~mm}$ and the diameter of the bolt holes is $6 \mathrm{~mm}$. The thickness in the region of the bolt holes is $3 \mathrm{~mm}$, and the thickness at the hub and the rim is $15 \mathrm{~mm}$. The Dimensions are given in Fig. 2.Meshing is done in ANSYS. The finite element mesh of the model is shown in the Fig. 3. below;

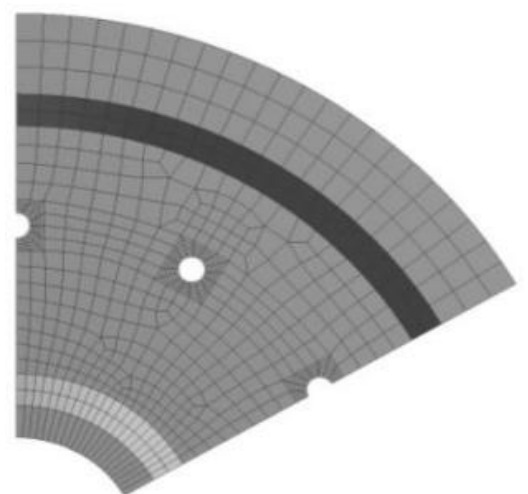

Fig. 3.Mesh model

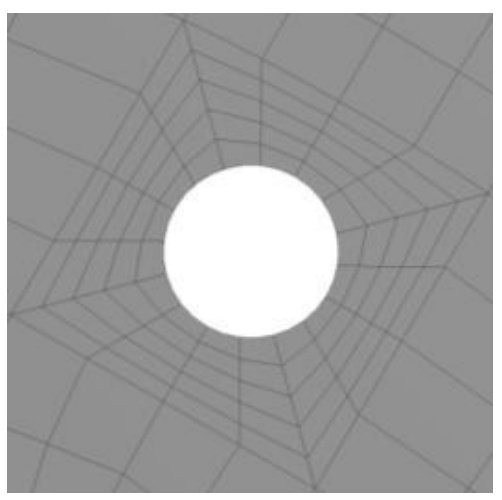

Fig. 4.Mesh around bolt hole region

The meshed model consists of 3225, 3D Brick elements. The mesh is densely captured in the bolt hole region as shown in Fig. 4. Five inflation layers are used around the bolt hole regions. The mesh is more concentrated in the bolt hole region where the stresses are to be studied.

The element quality checks were performed for the critical area in meshed model. The meshed model satisfies the acceptable parameters. The parameters and the actual values are given in Table- I. below;

Table- I: Quality check-critical areas

\begin{tabular}{|c|c|c|}
\hline Parameters & Actual value & Acceptable value \\
\hline Aspect Ratio & 1.9 & 1 to 4 \\
\hline Jacobian & 1.4 & $>0.7$ \\
\hline
\end{tabular}

The element quality parameters are within the acceptable range in bolt hole region. The disc material used in the FEA analysis of a disc was titanium alloy. Its ultimate tensile stress $\sigma_{\mathrm{u}} 1070 \mathrm{MPa}$, and yield stress $\sigma_{\mathrm{y}}$ is $930 \mathrm{MPa}$. The elastic modulus E is $96 \mathrm{GPa}$. The Poisson's ratio is 0.36 and the density $\rho$ is $4373 \mathrm{~kg} / \mathrm{m}^{3}$.

The loads, Boundary conditions and the analysis cases is given below:

Case(i) 15,000 RPM (or) $1570.79 \mathrm{rad} / \mathrm{s}$.

Case(ii) 45,000 RPM (or) $4712.38 \mathrm{rad} / \mathrm{s}$.

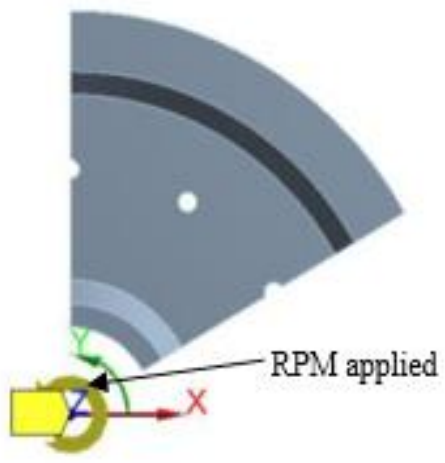

Fig. 5.Applying RPM

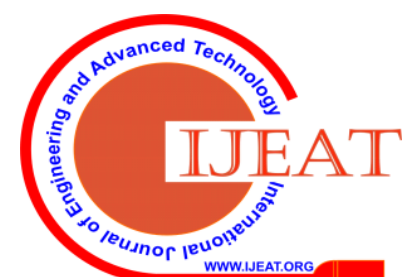




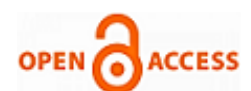

International Journal of Engineering and Advanced Technology (IJEAT)

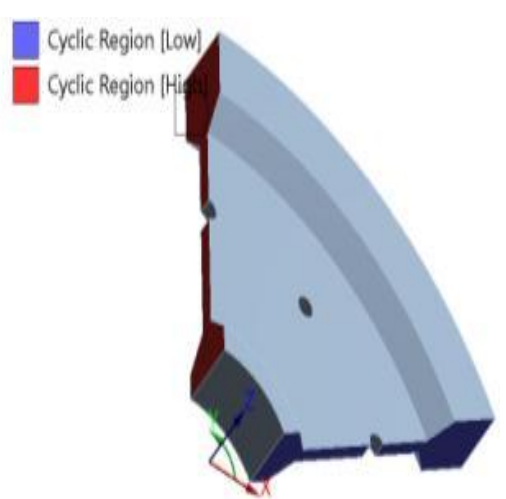

Fig. 6.Cyclic Symmetry Condition

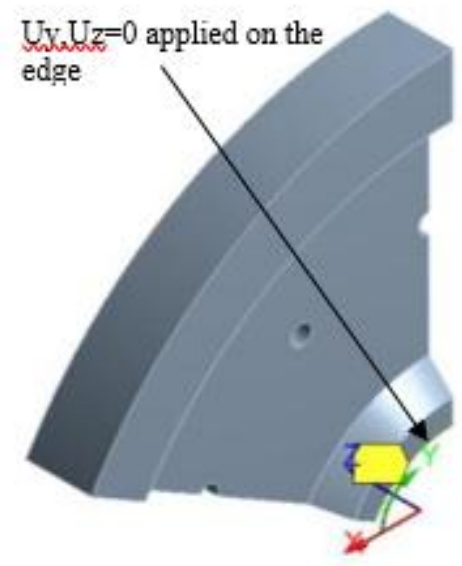

Fig. 7.In Cylindrical coordinate system

\section{RESULTS}

The following section consists of the detailed discussion of results for 15000 RPM and 45000 RPM. The stress and deformation plots are compared and analyzed for different rotational speed of 15000 RPM and 45000 RPM. The Stress variation across the surface of the disc between two bolt hole region and through the thickness of the disc in the bolt hole region is compared. Then the state of the stress in the bolt hole region is analyzed and discussed. Then the cyclic stress acting on the hole is discussed. Finally, the cyclic local stress strain response is discussed.

\section{A. Results Discussions 15000 RPM}

At 15000 RPM the following results were obtained. The Directional deformation and the various stress are obtained as shown in Fig. 8., Fig. 9., Fig. 10., Fig. 11., Fig. 12., Fig. 13. Below;

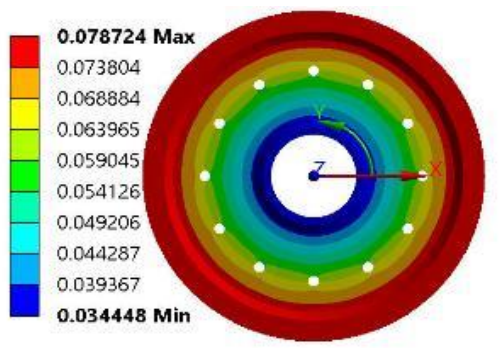

Fig. 8.Radial Deformation
ISSN: 2249 - 8958 (Online), Volume-9 Issue-4, April 2020

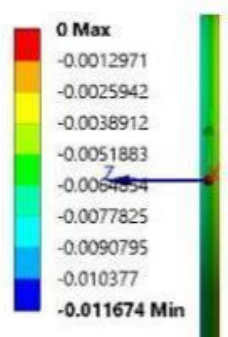

Fig. 9.Axial Deformation

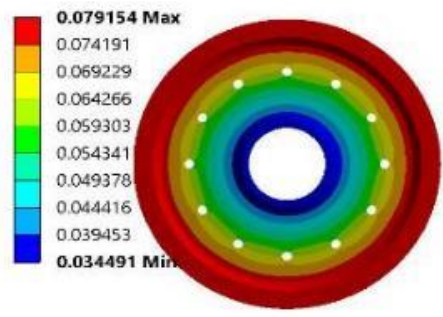

Fig. 10. Total Deformation

Maximum deformation at Rim in Radial direction is $0.078 \mathrm{~mm}$ due to centrifugal force pulling the disc outward as shown in the Fig. 8. Maximum deformation in Axial direction is $0 \mathrm{~mm}$ as shown in Fig. 9. Maximum deformation of $0.079 \mathrm{~mm}$ is observed on the rim of the disc as shown in Fig. 10.

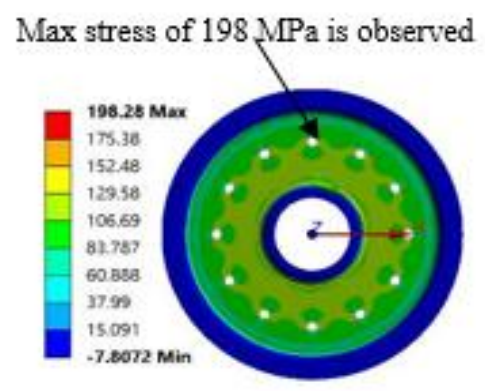

Fig. 11. Radial Stress

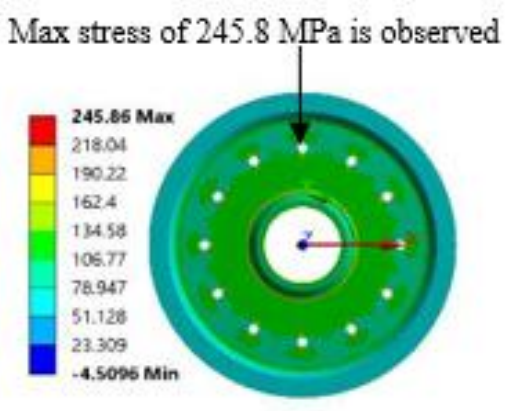

Fig. 12. Hoop Stress

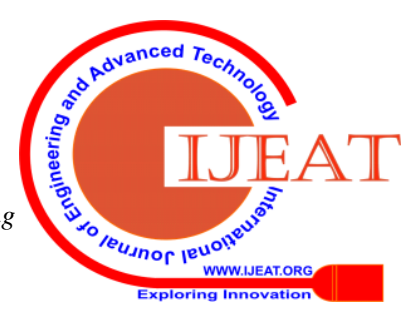




\section{Structural Design Research Through Finite Element Method (FEM) for a Compressor Disc}

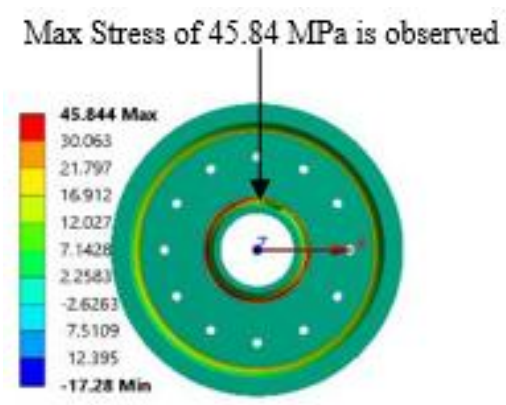

Fig. 13. Axial Stress

The radial stress is minimal in the hub and the rim. The maximum radial Stress is $198 \mathrm{MPa}$ and it is observed in all bolt hole regions of the disc as shown in Fig. 11.The maximum hoop stress is $245.8 \mathrm{MPa}$ and is observed in all bolt hole region as shown in Fig. 12.The maximum axial stress is $45.84 \mathrm{MPa}$ and it is observed in the region as shown in Fig. 13.

1) Radial Stress Variation Along Hole Thickness\& between two bolt holes

In the below section the variation of the radial stress through the thickness of the hole and between the bolt holes is discussed

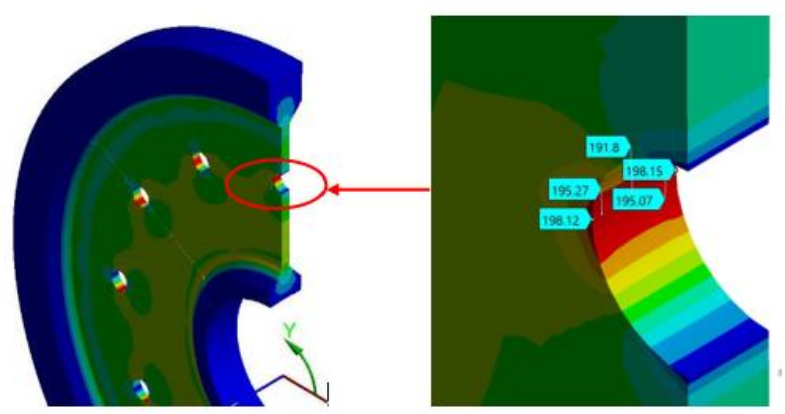

Fig. 14.Radial Stress region

Fig. 15. Radial Stress Variation through thickness

The maximum radial stress is found in the bolt hole region as shown in the Fig. 14. It is found that the stress $198 \mathrm{MPa}$ is varying through-thickness of the hole and the minimum stress $191 \mathrm{MPa}$ is found at the middle and is again gradually increasing towards the other edge of the bolt hole as shown in Fig. 15.

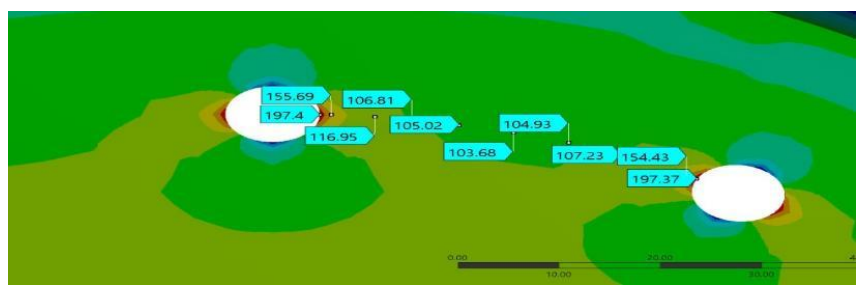

Fig. 16. Radial stress variation along the corner at 15000 RPM

The variation of stress between two bolt holes is seen in the Fig. 16.It is observed that the stress $(198 \mathrm{MPa})$ is gradually decreasing from the corner of the bolt hole region and it is found minimal(103.68 $\mathrm{MPa})$ at the middle and is gradually increasing again and found maximum(198 MPa) at the edge of the other bolt hole region. The Average Remote stress is $104 \mathrm{MPa}$.

2) Hoop stress Variation through thickness of hole\& along surface

A detailed study is done to understand the behavior of the hoop stress variation through the thickness of the bolt hole and between two bolt holes as shown in the Fig.17 and Fig.18.

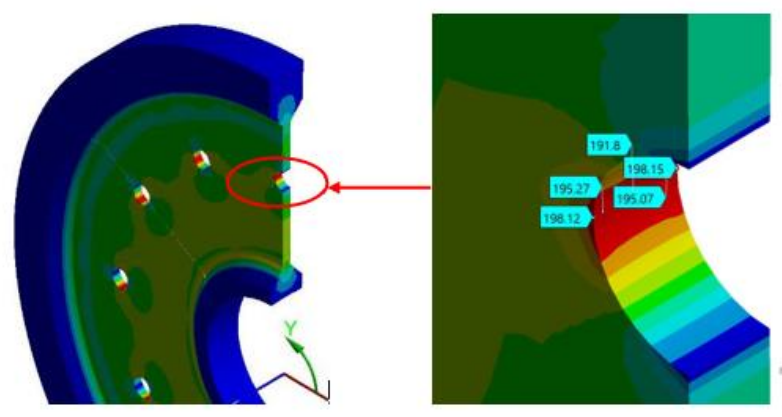

Fig. 17. Hoop Stress region

Fig. 18. Hoop Stress Variation through thickness

The maximum hoop stress is found in the bolt hole region as shown in the Fig. 17. It is found that the stress is varying through-thickness of the hole and the maximum stress (246 MPa) is found on the middle of the region as shown in Fig. 18.

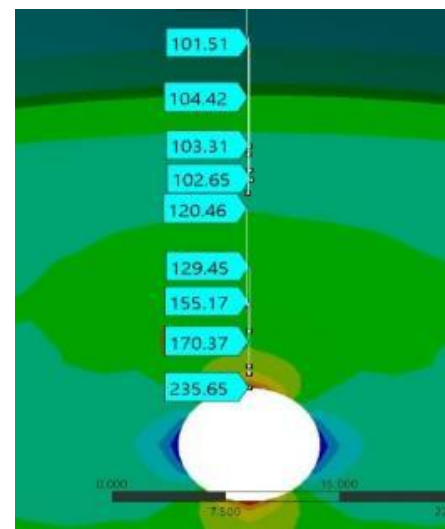

Fig. 19. Hoop stress variation along surface at 15000 RPM

The hoop stress is gradually decreasing from the edge of the bolt hole towards the other side of the disc as shown in Fig. 19. The stress value at the edge of the hole is $234 \mathrm{MPa}$. The hoop stress is maximum when compared with the radial stress acting on the rotating disc. The Average Remote stress is $104 \mathrm{MPa}$.

\section{B. Results Discussions 45000 RPM}

At 45000 RPM the following results were obtained. The Directional deformation and the various stress are obtained as shown in Fig. 20., Fig. 21., Fig. 22., Fig. 23., Fig. 24., Fig. 25. below;

Published By:

Blue Eyes Intelligence Engineering \& Sciences Publication

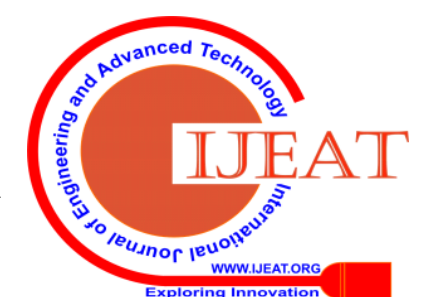




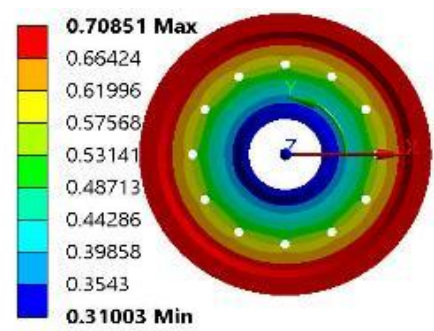

Fig. 20. Radial Deformation

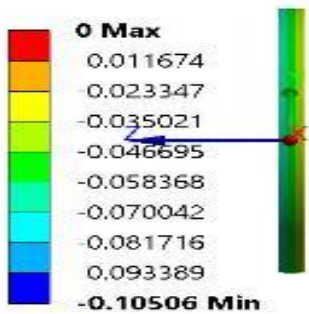

Fig. 21. Axial Deformation

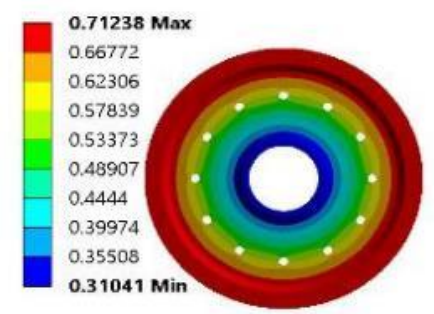

Fig. 22. Total Deformation

Maximum deformation in Radial direction is $0.7 \mathrm{~mm}$ at Rim due to centrifugal force pulling disc outward as shown in Fig. 20. Maximum deformation in Axial direction is $0 \mathrm{~mm}$ as shown in Fig. 21. Maximum deformation of $0.7 \mathrm{~mm}$ is observed on the rim of the disc as shown in Fig. 22.

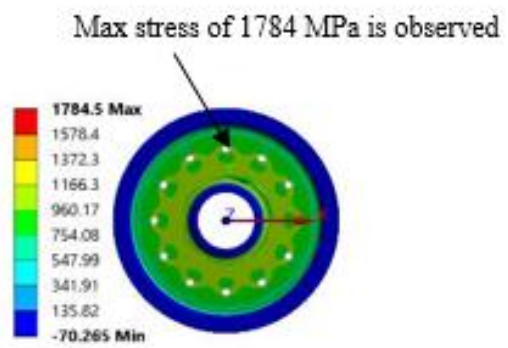

Fig. 23. Radial Stress

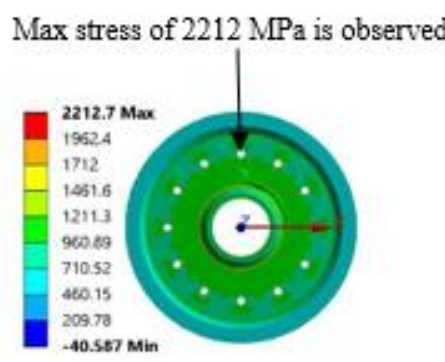

Fig. 24. Hoop Stress

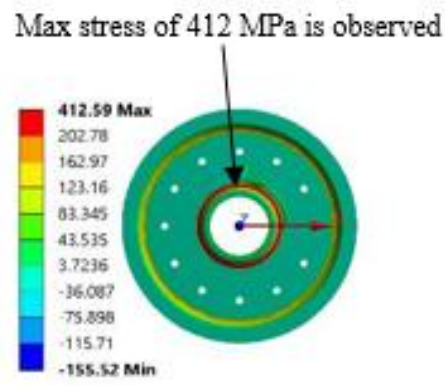

Fig. 25. Axial Stress

The Radial stress is minimal in the hub and the rim. The maximum radial Stress is $1784 \mathrm{MPa}$ and it is observed in all bolt hole regions of the disc as shown in Fig. 23.The maximum hoop stress is $2212 \mathrm{MPa}$ and is observed in all bolt hole region as shown in Fig. 24. The maximum axial stress is $412 \mathrm{MPa}$ and it is observed in the region as shown in Fig. 25.

1) Radial Stress Variation along the hole thickness\& between bolt holes

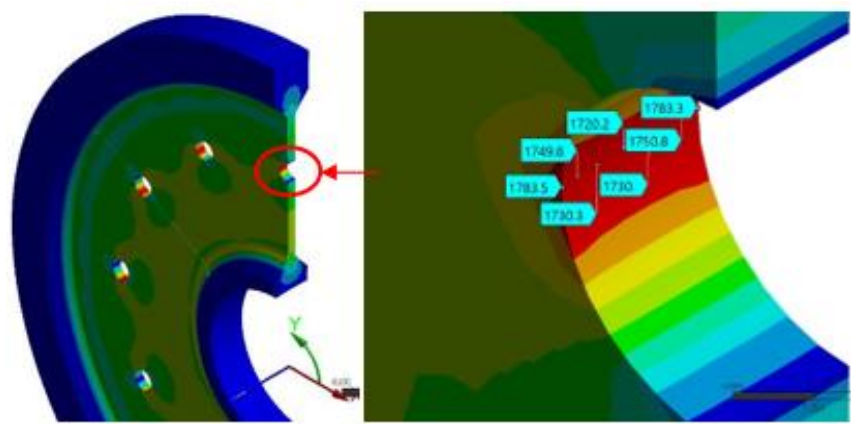

Fig. 26. Radial Stress region

Fig. 27. Radial Stress Variation through thickness

The maximum radial stress is found in the bolt hole region as shown in the Fig. 26. It is found that the stress $1784 \mathrm{MPa}$ is varying through-thickness of the hole and the minimum stress $1720 \mathrm{MPa}$ is found at the middle and is again gradually increasing towards the other edge of the bolt hole as shown in Fig. 27.

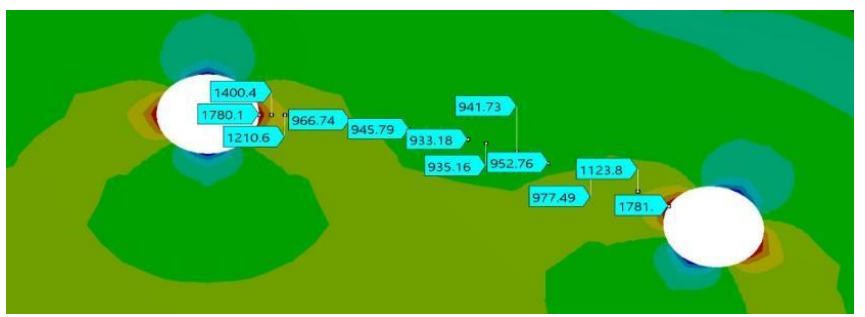

Fig. 28. Radial stress variation along the corner at 45000 RPM

The variation of stress between two bolt holes is seen in the Fig. 28.It is observed that the stress $(1784 \mathrm{MPa})$ is gradually decreasing from the corner of the bolt hole region and it is found minimal (933 $\mathrm{MPa}$ ) at the middle and is gradually increasing again and found maximum (1784 MPa) at the edge of the other bolt hole region. The Average Remote stress is $900 \mathrm{MPa}$.

Published By:

Blue Eyes Intelligence Engineering \& Sciences Publication

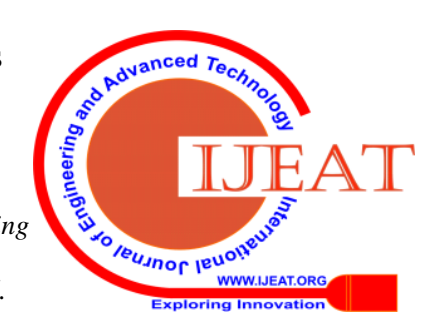


2) Hoop stress Variation through thickness of hole \&along surface
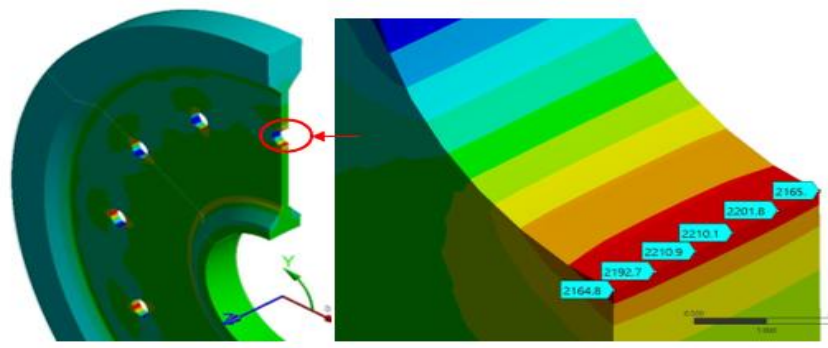

Fig. 29. Hoop Stress region

Fig. 30. Hoop Stress Variation through thickness

Fig. 31.

The maximum hoop stress is found in the bolt hole region as shown in the Fig. 29. It is found that the stress are varying through-thickness of the hole and the maximum stress (2212 $\mathrm{MPa}$ ) is found in the middle region as shown in Fig. 30.

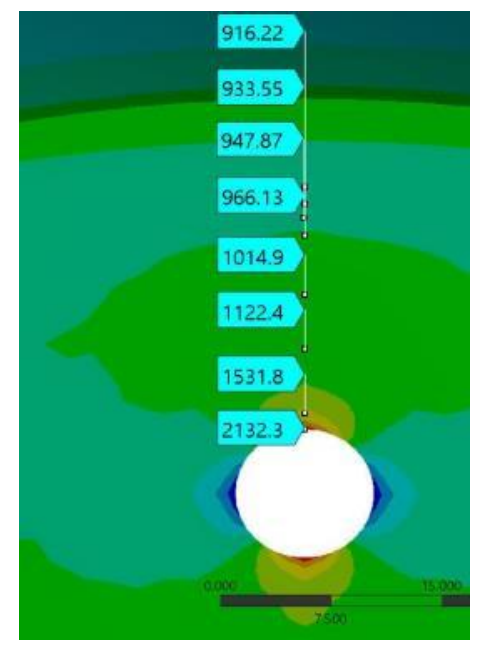

Fig. 32. Hoop stress variation along surface at 45000 RPM

The hoop stress is gradually decreasing from the edge of the bolt hole towards the other side of the disc as shown in Fig. 31. The stress value at the edge of the hole is $2132 \mathrm{MPa}$. The hoop stress is minimum when compared with the radial stress acting on the rotating disc. The Average remote stress is $900 \mathrm{MPa}$.

\section{Results Detailed Discussions}

In this section, the state of stress around the bolt hole region, the radial cyclic stress, the cyclic stress strain response of the disc is discussed.

The stress acting on the bolt hole region is equi-biaxial. At $45000 \mathrm{rpm}$, the radial/hoop remote stress is $900 \mathrm{MPa}$ and $\lambda^{*}=1$. where $\lambda$ is the ratio of stress along $\mathrm{x}$-axis to that of $\mathrm{Y}$-axis. At $15000 \mathrm{rpm}$, the radial/Hoop remote stress is $104 \mathrm{MPa}, \lambda^{*}=1$.

According to Theory of Elasticity,

- Hoop stress at the edge of hole (2212 MPa) is more than twice the Remote stress (900 MPa)

- Since the remote stress (900 MPa) is greater than half the yield strength $(930 \mathrm{MPa})$ of the material the hole edge undergoes plastic yielding.

At the minimum rotation speed of 15000 RPM, the radial stress is equal to $104 \mathrm{MPa}$ and at the maximum rotation speed of $45000 \mathrm{RPM}$, the radial stress is equal to $900 \mathrm{MPa}$.
Stress Ratio $=\frac{\sigma_{\min }}{\sigma_{\max }}=\frac{104}{900}=0.1$

The cyclic stress amplitude is $796 \mathrm{MPa}$ which is less than the material yield strength (930 MPa). Therefore, after plastic deformation, elastic shakedown occurs and there is no cyclic plasticity around the hole.

Further, the cyclic local stress strain response for elastic material and for the elastic plastic material is compared and analysed. The details are as follows,

During first half cycle, local plastic yielding would occur around the hole edge when the stress reaches $900 \mathrm{MPa}$ (Remote stress).

For elastic material the stress concentration factor is 2.3 and hence during cyclic loading the stress at the edge of the hole varies from $70 \mathrm{MPa}$ to $1496 \mathrm{MPa}$ during the rotation.

Stress Concentration factor $K_{\mathrm{t}}=\frac{\sigma_{\max }}{\sigma_{\min }}=\frac{2212}{900}=2.4$

Using Neuber's rule;

Total strain $=\varepsilon_{0}=\frac{\sigma_{y s}}{E}=\frac{930 * 10^{6}}{96 * 10^{9}}=0.0096$

Yield(Elastic)Strain $=\varepsilon_{\text {total }}=\frac{\left(K_{\mathrm{t}} * \sigma\right)^{2}}{\left(\sigma_{y s} * E\right)}=0.0522$

Thus, total strain (0.0522) is twice the yield(elastic) strain (0.0096) of the material.

\section{CONCLUSION}

The compressor disc model with bolt holes is analyzed for Centrifugal force. When the Disc with a bolt hole Is made to rotate with constant velocity the hoop stress is higher than the radial stress. The maximum stress is found in the bolt hole region. The summary of the results obtained are tabulated in the Table-II given below,

Table- II: Results Summary

\begin{tabular}{|c|c|c|}
\hline $\begin{array}{c}\text { Rotational Velocity } \\
\text { (RPM) }\end{array}$ & $\mathbf{1 5 0 0 0}$ & $\mathbf{4 5 0 0 0}$ \\
\hline $\begin{array}{c}\text { Max Radial Sress } \\
\text { (Mpa) (in bolt hole) }\end{array}$ & 198 & 1784 \\
\hline $\begin{array}{c}\text { Max Hoop Stress } \\
\text { (Mpa) (in bolt hole) }\end{array}$ & 246 & 2212 \\
\hline $\begin{array}{c}\text { Remote Stress } \\
\text { (Mpa) }\end{array}$ & 104 & 900 \\
\hline
\end{tabular}

From the results summary it's clear that the stress acting on the bolt hole region is equi -biaxial. The hoop stress is more than the Radial stress for both the rotational velocity. According to Theory of Elasticity, Hoop stress at the edge of hole $2212 \mathrm{MPa}$ ) is more than twice the Remote stress (900Mpa). Since the remote stress $(900 \mathrm{MPa})$ is greater than half the yield strength (930MPa) of the material the hole edge undergoes plastic yielding. The cyclic stress amplitude is 796 $\mathrm{MPa}$ which is less than the material yield strength (930 MPa). Therefore, after plastic deformation, elastic shakedown occurs and there is no cyclic plasticity around the hole.

Published By:

Blue Eyes Intelligence Engineering \& Sciences Publication 
For elastic material the stress concentration factor is 2.4 and hence during cyclic loading the stress at the edge of the hole varies from $246 \mathrm{MPa}$ to $2212 \mathrm{MPa}$ during the rotation. Thus, total strain (0.0522) is twice the yield(elastic) strain (0.0096) of the material.

\section{FUTURE WORK}

Since the cyclic stress amplitude at the hole edge is equal to $796 \mathrm{MPa}$. Slightly above $2 / 3^{\text {rd }}$ material yield strength of $930 \mathrm{MPa}$, Conventional Linear Elastic Fracture Mechanics should be still applicable to quantifying the growth of short cracks emanating from the hole. However, elastic-plastic stress distribution along prospective crack path is required to determine max. stress intensity factors, while, the range of stress intensity factor can be determined using elastic solutions [1]. Regarding the validation of the results through experiments, some experimental tests are already conducted in literature. Because experimental validation of these type of disc is very expensive and hard to be conducted. Nevertheless, the Experimental results will be in correlation with the Finite element analysis. For a future studies one can perform Rig test for a given Disc model to compare the experimental results with the numerical results obtained from our studies.

\section{REFERENCES}

1. Zhuang, W. Z. (2000). Prediction of crack growth from bolt holes in a disc. International journal of fatigue, 22(3), 241-250.

2. Çallioğlu, H., Bektaş, N. B., \& Sayer, M. (2011). Stress analysis of functionally graded rotating discs: analytical and numerical solutions. Acta MechanicaSinica, 27(6), 950-955.

3. Kumar, M., Ahmad, S., Singh, I. V., Rao, A. V., Kumar, J., \& Kumar, V. (2018). Experimental and numerical studies to estimate fatigue crack growth behavior of Ni-based super alloy. Theoretical and Applied Fracture Mechanics, 96, 604-616.

4. Claudio, R. A., Branco, C. M., Gomes, E. C., \& Byrne, J. (2002). Life prediction of a gas turbine disc using the finite element method. 8AS Jornadas de Fractura.

5. Beres, W., Zhang, Z., Dudzinski, D., Chen, W. R., \& Wu, X. J. (2014). Residual Life Assessment of a Critical Component of a Gas Turbine: Achievements and Challenges. In ASME Turbo Expo 2014: Turbine Technical Conference and Exposition. American Society of Mechanical Engineers Digital Collection.

6. Kumar, R., Ranjan, V., Kumar, B., \& Ghoshal, S. K. (2018). Finite element modelling and analysis of the burst margin of a gas turbine disc using an area weighted mean hoop stress method. Engineering Failure Analysis, 90, 425-433.

7. SartiLeme, A. D., Creci, G., Barbosa de Jesus, E. R., Rodrigues, T. C., \& Menezes, J. C. (2019). Finite element analysis to verify the structural integrity of an aeronautical gas turbine disc made from inconel 713LC superalloy. In Advanced Engineering Forum (Vol. 32, pp. 15-26). Trans Tech Publications.

8. Vyas, N. S., \& Rao, J. S. (1997). Dynamic stress analysis and a fracture mechanics approach to life prediction of turbine blades. Mechanism and machine theory, 32(4), 511-527.

9. Horgan, C. O., \& Chan, A. M. (1999). The pressurized hollow cylinder or disk problem for functionally graded isotropic linearly elastic materials. Journal of Elasticity, 55(1), 43-59.

10. Durodola, J. F., \& Attia, O. (2000). Deformation and stresses in functionally graded rotating disks. Composites Science and Technology, 60(7), 987-995

\section{AUTHORS PROFILE}

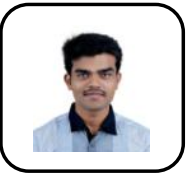

Merin Christo $\mathbf{J}$, is graduated in Aeronautical Engineering from Jeppiaar Engineering College, Chennai. Currently he is a PG student in CHRIST (Deemed to be university), Bangalore. He has attended various national and International conferences and presented his papers.
His area of interests are Modeling and Simulation, Material Science, Composite materials \& Failure Analysis.

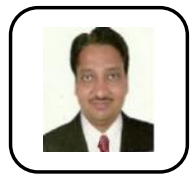

Badarinath B G, is Currently the Managing Director of Renprotech Solutions Pvt. Ltd, Bangalore. He is Globa Technical Leader with 31+ years of combined Aerospace, Oil Hydraulics \& Industrial product experience, out of which 18 years in Technology \& Senior Executive Management role led Offshore Innovation center for New products, Innovation, Current products margin improvements- VAVE, Manufacturing Process Automation, Proto lab, Simulation\& Global sourcing.

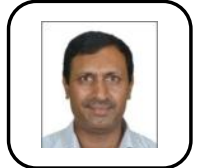

Dr. Shivakumar S, is a Assistant Professor at Christ (Deemed to be University), Bangalore. He Completed his Graduation from Bangalore University. He has a $15+$ years of Industrial Experience. His area of interest is Hyperelastic materials. He is well versed in doing Structural, thermal, electro-thermal, Modal, PSD, and drop test simulations. He has attended various National and International Conferences.

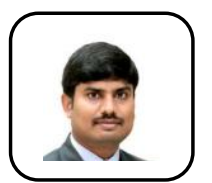

Umesh V, is a Assistant Professor at Christ (Deemed to be University), Bangalore. He is currently pursuing his $\mathrm{PhD}$. He Published various papers and books in conference Proceedings. His area of interest is CAD/CAM, Robotics, Manufacturing and Composites.

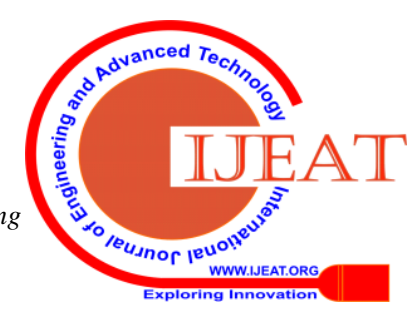

